\title{
A Novel Framework of Success Using of E-Assessment During Corona Pandemic
}

\author{
https://doi.org/10.3991/ijet.v16i12.22063 \\ Sultan Refa Alotaibi \\ Shaqra University, Shaqra, Saudi Arabia \\ sultanrefa@su.edu.sa
}

\begin{abstract}
Recently, the concept of e-learning has spread widely in many universities around the world under the current circumstances (the Corona pandemic), which made e-learning in many countries' compulsory for all its students in universities in order not to stop the educational process. In light of the great improvement that some countries are witnessing in information and communications technology (ICT) sector and e-learning platforms, it has become very important to pay attention to the electronic assessment (e-assessment) side, which appeared side by side with e-learning systems. This kind of assessment is overcome some of the limitations in the paper-based assessment. One of the advantages of an electronic assessment (e-assessment) is the ability to provide feedback to the student immediately. Most of the universities around the world were providing e-learning to their students as a development option for the education process, on condition that they attend to take the exam in the universities in attendance. But in the Corona crisis, this thing was not possible, especially in subjects that have very large number of students, so (e-assessment) has become a basic option for most universities in order to achieve the principle of social distancing. Therefore, this paper examines the factors that affect academic acceptance of (e-assessment) system.
\end{abstract}

Keywords -E-Assessment, E-Learning, Online Exams, Success Factors, Assessment Adoption

\section{Introduction}

Assessment is one of the basic elements in education at all levels of the university that brings learning outcomes and the qualification achievement journey [1] [2]. Recently, information and communication technology has been used in education at various stages of teaching, so assessment is one of the stages of education that has been improved through the use of information and communication technology [1]. With the increase in the number of students enrolled in universities around the world, whether the environment is traditional or e-learning, the usual methods of assessment (the physical paper-based test) have become insufficient in terms of time and effort [4]. Therefore, e-assessment has become an attractive option for educational institutions looking to solve the problems that exist in the traditional way in the assessment 
process and whose difficulty increases with the increase in the number of students [2]. The assessment process in the electronic environment is the same as in the traditional method of validity, fairness and flexibility [2]. Therefore, the electronic assessment is carried out to help evaluate a large number of students at the same time to obtain accurate and fast results [1] [11] the electronic assessment is defined as an evaluation that is done electronically, where ICT is employed to conduct the entire assessment starting with presenting, saving and correcting questions, and ending with showing results.

In addition, students prefer electronic assessment because they feel in control, especially if there are good interfaces for the assessment platform and also the presence of simulation programs that closely resemble real learning environments and it is quick and easy to use. The electronic assessment also provides immediate feedback compared to the paper-based tests, which helps to improve the level of learning. Moreover, the electronic assessment helps students who are in remote areas to submit their exams in their own places without having to go to their universities. These tests can be taken at their convenience, providing flexibility for students to take the exams [10].

The paper test takes time for teachers to correct each paper, but using an electronic assessment will save the teacher time. In addition, direct feedback from the assessment allows the teacher to find students' unclear points and misconceptions. There are some studies which have been conducted to evaluate the effect of computer-based tests $[1,3,7,9,11,13-20]$; therefore, the findings of these studies were limited by several factors, including 1) the continuous change in software and hardware technology; 2) Improve test taker's computer skills and knowledge; 3) Difficulty using a randomized controlled study design to provide a direct assessment of the impact of the test format (electronic versus paper) on test-taker performance 4) A wide range of academic levels are assessed; 5) Lack of consistency in the testing environment, such as time allowed, question design, and observation [21-25].

Therefore, many universities during the Corona crisis began to rely on eassessment, but there is little research that discussed the issues of adopting eassessment in universities around the world. Therefore, there is an urgent need to study the factors that influence academics to accept electronic assessment. Therefore, this paper examines the influencing factors that influence academics to adopt electronic assessment.

\section{$2 \quad$ Literature Review}

Authors in [1] investigated the factors influencing academics to accept Eassessment. They developed a Model of Acceptance of E-assessment (MAE). The results has shown that Attitude had an impact on Saudi academics' behavioral intention to accept E-assessment however; Perceived Behavioral Control had no effect on their intention to accept E-assessment. Perceived Ease of Use and Perceived Usefulness were found to have the most impact on Attitude. Also, they found that Age was 
examined as a moderating factor that might affect the relationships between Perceived Behavioral Control, Attitude, Behavioral Intention, and Subjective Norm.

Authors in [2] investigated that the students' perceptions of using e-assessment at the Institute of Development Management in Eswatini. This study used mixed research methods quantitative and qualitative. Therefore, this study was gathered from the students and the lecturers from through interviews, questionnaires and observations. The results have shown that the students' perceptions of e-assessment has positive effect on their learning activities.

Authors in [5] designed a virtual reality (VR) game-based e-assessment application because they want to understand whether the type of e-assessment can affect students' performance or not. This study found that virtual reality game-based e-assessment application is a good method to improve learners' engagement in evaluation meeting. However, this study found some students might face some problems when they are using this kind of e-assessment to do a lack of experience in its use.

Authors in [6] investigated the challenges and benefits implementing the self and peer assessment. This study used one method, which is qualitative method (interview) with 13 Australian academics. This study found five challenges and seven themes of the benefits. This paper found that the academics have showed a strong belief in the power of self and peer assessment.

Authors in [8] explored the students' perceptions of using E-assessment at Saudi Electronic University. This university implemented this kind of assessment in the learning management system. The findings have shown the students had positive perceptions of using e-assessment and valued its features such as unbiased grading and immediate feedback.

\section{Motivations}

Some studies have indicated that many countries have resorted to total reliance on e-learning platforms in order to ensure that the educational process does not stop in light of the conditions that the world is going through due to the Coronavirus crisis. Therefore, currently, electronic assessments are considered an important tool and an effective way to continue the educational process, which has recently undergone several obstacles due to this crisis. Therefore, it became necessary to identify the important factors in adopting electronic assessments from the point of view of students and academics and to identify the most important problems that they face while performing this. Therefore, these factors and problems will be summarized in this paper. Also, based on that, integrated model for electronic assessments will be presented from both side (students- academic).

\section{$4 \quad$ Methodology}

This research paper has been considered as exploratory research since it investigates the acceptance of e-assessment in Saudi Arabia from both side (studentsacademic) perspective, which has not been previously explored. This paper is ex- 
pected to add to a better understanding of the nature of the acceptance of eassessment. Therefore, it became necessary to have integrated framework which includes controls and procedures that contribute to the success of accepting eassessments based on the points of view from academic and students perspective.

Therefore, to achieve the main objective of this paper, it is very an important to used qualitative way, because this approach is based on the collection and analysis of reactions and statements, voices, videos, words and actions.

The qualitative approach usually has presented the information in amusing verbal explanation. This helps many researchers to collect the information in short time and flexible way, to make this approach more dynamic. also, It is considered as explore the problems in daily affairs and makes these issues more familiar to the public at large scale. In addition, this approach is drawn conclusions from the view point of the participants of the interviews. The most methods used in the qualitative way are individual interviews and focus group discussion and direct observation of the participant.

Focus groups approach involved a small number of the participants (normally made up of 6 to 12 participants) controlled by a catalyst that has a well understanding of participants as well as attitude applicable to a given study [11-15]. This approach has tried to collect the data concerning the feelings and opinions a small number of the participants with a certain experience and assesses how they come up with the feelings [26-30].Therefore, this paper used two Focus groups in order to obtain information that would contribute to building integrated framework which includes controls and procedures that contribute to the success of accepting e-assessments based on the points of view from academic and students perspective. Table 1 presents brief information about the participants in both groups. The date was collected from Shaqra university.

Table 1. The distribution of participants joined the E-assessment process.

\begin{tabular}{|l|l|l|}
\hline \multicolumn{1}{|c|}{ The groups } & \multicolumn{1}{|c|}{ The participants } & \multicolumn{1}{c|}{ The college } \\
\hline \multirow{5}{*}{ Students Group } & The first participant & College of science \\
\cline { 2 - 3 } & The second participant & College of medicine \\
\cline { 2 - 3 } & The third participant & College of computing \\
\cline { 2 - 3 } & The fourth participant & College of computing \\
\cline { 2 - 3 } & The fifth participant & College of computing \\
\cline { 2 - 3 } & The sixth participant & College science \\
\hline & The seventh participant & College of engineering \\
\hline \multirow{5}{*}{ Academic Group } & The first participant & College of computing \\
\cline { 2 - 3 } & The second participant & College of computing \\
\cline { 2 - 3 } & The third participant & College of computing \\
\cline { 2 - 3 } & The fourth participant & College of engineering \\
\cline { 2 - 3 } & The fifth participant & College of computing \\
\cline { 2 - 3 } & The sixth participant & College of engineering \\
\hline & The seventh participant & engineering \\
\hline
\end{tabular}




\subsection{Findings}

This paper has examined a set of factors and challenges that guide the acceptance of electronic assessments in the form of steps. The first step is to collect some information about the benefits and elements that contribute to accepting electronic assessments from the students' point of view. The second step is to collect the most important difficulties and problems that students face when using electronic assessments. The third step is to collect some information about the benefits and elements that contribute to accepting electronic assessments from the academic point of view. In the fourth step, the most important obstacles that hinder acceptance of electronic assessments have been collected. All previous steps were taken in order to achieve the last step, which is a building integrated framework, which includes controls and procedures that contribute to the success of accepting e-assessments based on the points of view from academic and student's perspective.

\section{The Factors Affecting the Adoption E-Assessment}

This subsection mainly focuses on data collected from students in order to obtain the most important features and factors in the first stage. After that, information was obtained from the students' side about the difficulties they are facing when using electronic assessments. These factors are shown in Figure 1 and described in the following:

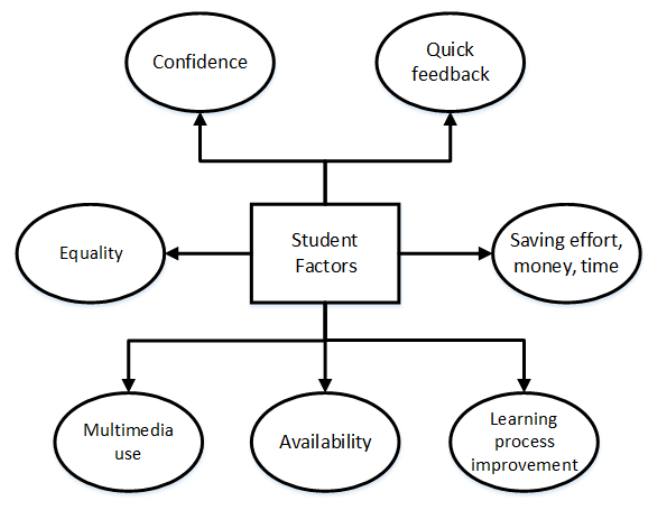

Fig. 1. Student factors affecting the adoption of e-assessment.

\subsection{Quick feedback}

The electronic assessment has the ability to quickly obtain feedback. Therefore, many participants emphasized the speed of obtaining results. For example, There are many benefits to all students when using electronic assessments, and the number one benefit to me is that I know the test results quickly and it is better than the traditional way to correct the tests. 
In addition, another person confirmed this point (benefit) so that the result appears to him directly upon completion of the test: I feel satisfied that when I finish the online assessments, I see the test results. In addition, using electronic assessments, students receive a detailed report of correct and false results, as confirmed by one of the participants, for example: Once electronic assessments are submitted, I will receive a report of the score and location of correct and wrong answers.

\subsection{Confidence}

Confidence in the use of electronic assessments is very important for many participants, as bias does not exist, as one of them emphasized this, for example: The biggest benefit is that there is no bias regarding the correction of the test as I have great confidence in electronic assessments.

\subsection{Learning process improvement}

The existence of electronic assessments has become important in recent times, especially in the circumstances of the Corona pandemic. Therefore, electronic assessments have made the learning process continuous. There is an improvement in that process because electronic assessments reveal strengths and weaknesses. This was confirmed by one of the participants when he said: The abundance of electronic assessments is a motivation for us, as it reveals the strengths and weaknesses of students and mine in various aspects and thus there will be an improvement in the learning process.

In addition, electronic assessments are important to be present because they improve and make education more effective, as one of the participants mentioned that: Electronic assessments, in my view, improve the educational process and make it more effective because they quickly reveal my existing defects, which are weaknesses.

Moreover, everyone agreed on the importance of electronic assessments as improving the educational process, as distinguished students will be discovered when one of the participants says so: I would like to add some points to my classmates talks that online assessments are good because they discover outstanding students and embrace strengths.

\subsection{Multimedia use}

Diversity in the use of teaching methods and tests constitutes a new method in the modern style of education, and the use of multimedia is one of the modern methods when one of the participants confirmed that: Multimedia can be used as a form of electronic assessment as an alternative to regular tests. Linking electronic assessments directly with the student, by adding video clips in order to make the student more keen and interested in using it many times when one of the participants mentioned this when he said: In my opinion, the presence of videos in electronic assessments as a 
type of question makes me more eager to continue the test and I am looking forward to using it on more than one topic.

On the other hand, traditional tests have flaws and they are not interactive, and when adding some improvements such as audio or video clips, it makes electronic tests distinctive, and one of the participants confirmed this: I strongly agree with my colleagues that traditional exams are somewhat boring, but when adding audio or video clips, students are encouraged to accept electronic assessments.

\subsection{Equality}

One of the important features of electronic assessments is the presence of equality and fairness among all students, and one participant mentioned that when he said: In my opinion, the element of equality exists among all of my colleagues when applying electronic assessments. Some participants mentioned the importance of question banks for each subject in order to provide the concept of equality, which is present when applying electronic assessments when he said: I think that having a question bank is very important so that this bank divides the questions into parts (easy - medium - hard) so that students appear equally, and it makes me feel equal. Also, everyone proved that the element of equality is important and one of the participants confirmed that when he said: I agree with my colleagues that the equality component is very important in the tests and that electronic assessments achieve this goal.

\subsection{Availability}

The availability of electronic evaluations at different times is one of the features that distinguish these types of evaluations from others, and one of the participants confirmed this when he said: Online assessments allow me to take the test whenever I want. This feature (availability) was confirmed by many participants, for example: I can access reviews online 24 hours in seven days. The availability of electronic evaluation in a specific period of time constitutes a hindrance for many students, as one of the participants mentioned that point, for example: I think that electronic assessments have an important benefit for me and my colleagues, which is that the test is available to us at any time, especially the tests that are not limited to a specific period of time and period.

Some students feel comfortable when the electronic assessment is not restricted to a time or a period of time when one of the participants mentioned this when he said: I have experience with electronic assessments, so the doctor gave us the test for a week, and this means that I can access it at any time that suits me.

\subsection{Saving effort, money and time}

One of the advantages that distinguish the electronic evaluation from other assessments is the saving of time, and one of the participants mentioned this when he said: For me, the remote test reduces travel time. Also, one of the students mentioned that electronic assessments provide effort, and this thing was mentioned by more than one 
participant, for example: I live very far from my university, so the remote test has brought the university close to me, so that it saves me time and effort. Moreover, electronic assessments save money and travel time and this feature was confirmed by one of the participants when they said you: I believe that online assessments will be a strategic option for some countries, especially when university students are not from the same city as the university. So that it saves all students from traveling from their cities outside the city in which their universities are located. So in my view, online assessments will save students, effort, money and travel time.

\section{Difficulties That Students Face Using Electronic Assessment}

There are many problems that may affect students' use of electronic assessments, directly or indirectly. Therefore, a group of the most important problems were collected from the students 'point of view, as shown in Figure 2. These difficulties are described in the following:

\subsection{Poor infrastructure}

The most important big problem in the technical field is poor infrastructure, so one of the participants confirmed this when he said: In my opinion, there is some infrastructure weakness in conducting electronic assessment. One of the problems related to the infrastructure is the pressure on the systems and their use by a number of users. One participant mentioned that when he said: I support my colleague in what he said, that the e-learning platform has some problems that make it unable to take electronic exams, especially if there are a large number of students registered in the course.

One of the problems related to the infrastructure is the absence of technical support, which directly affects the use of electronic assessments, and this was confirmed by one of the participants: I have experience in one of the electronic assessments, and I have not been able to complete the tests. The reason is that the platform is not ready or the number of students is large, which made this a great burden on the platform.

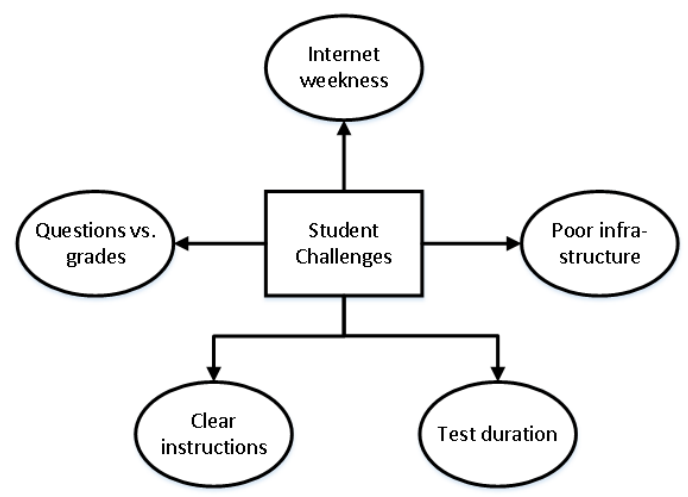

Fig. 2. Challenges facing students. 


\subsection{Internet weakness}

There are many difficulties that face many students when using some systems, and among those difficulties is the weakness of the Internet, which is a direct obstacle to the use of electronic assessments. Because there are some cities that differ in terms of connection speed, and this matter was confirmed by one of the participants when he said: I am having a problem with poor internet in the city in which I live, which makes this a hindrance for me to take the tests remotely.

Internet interruption may cause some problems, the most important of which is tension, which is an obstacle to completing the test well, as one of the participants mentioned: I have a problem with completing some remote tests, which are long, as the Internet is cut off from time to time, which causes me embarrassment and tension during the performance of the test. One of the participants confirmed this when he said: I say it honestly, what I fear most in using electronic assessment is the weakness of the Internet.

\subsection{Questions correspond to grades}

The test is an obsession for all students, and that obsession lies in the position of the distribution of scores on the tests. One of the participants mentioned this thing when he said: The problem that my colleagues and I have is grading questions. The distribution of grades must be in parallel with the number of questions, so that the test is a way to measure and evaluate the student well, and one of the participants mentioned this: I agree with my colleague in what he said that there are long questions and you find that there are few marks on them and sometimes short questions with high scores. We hope this will be taken into account in the future.

\subsection{Test duration}

Establishing sufficient test time for students during their exam is very important and one participant mentioned this thing when he said: Some materials are tested in a short time, which is a matter of our concern. In addition, the mother of the test period was confirmed very important in terms of psychological stability during the performance of the test and that the questions and answers to them in terms of thinking and writing were synchronized with time and did not require much time in terms of thinking or analysis, etc. And this matter was mentioned by one of the participants when he said: Sincerely, I am talking about electronic evaluation, it must be taken into account that there is flexibility in time and that sufficient additional time must be added in case of multiple questions and require a detailed answer, especially if the questions are open and not multiple-choice.

\subsection{Clear instructions for the exam}

There is ambiguity in many instructions about how to use electronic assessments and this thing was mentioned by one of the participants when he confirmed this by 
saying: Sometimes we have trouble recognizing the online test instructions. There is a difference in the instructions from subject to article, and this matter constitutes a confusion for the students. Therefore, there must be a standardization of the instructions for all courses, and this thing was mentioned by more than one participant, for example: From my point of view, there must be clear and uniform instructions for all the courses we study, because we are surprised that each course has its own instructions. This is a concern for us. Giving enough time to explain instructions on how to operate electronic assessments is very important and confirming it by a participant when he said: I think that there is a need to educate us about how to take electronic exams a week before the date of the test, which helps us prepare to enter the exam.

\section{Factors that Assist in Adopting Electronic Assessments for Academic Staff}

There are many elements and factors that help academics in adopting electronic assessments, and these elements are as shown in Figure 3. These factors are described in the following:

\subsection{Usefulness}

One of the biggest elements through which electronic assessments are approved by academics is the desired benefit of this type of test, as confirmed by one of the participants, for example: I use electronic student assessments because they are useful for students and myself. Some academics have confirmed that there is a speedy response to obtaining feedback, which facilitates the understanding process of students, for example: From my point of view, electronic tests have many benefits, the most important of which is that they are useful for students in improving understanding of information because feedback is quick in this type of exam.

Identifying coffee points and weaknesses is very important to improve the educational process, and this thing was emphasized by one of the participants: I believe that electronic tests are useful in identifying weaknesses and thus seeking to improve them.

\section{2 $\quad$ Ease of use}

There are no difficulties that academics may face in adopting electronic assessments, and also there will be no difficulties faced by students, and this thing was mentioned by one of the participants: I think that the new generation does not face technical problems, so using the electronic test is easy for them. Most students have smart devices, and this thing is that it is easy for technology to be used in many of their different life matters, so one of the easy things to use is electronic assessments and this was confirmed by one of the participants when he said: I watch my students during the lecture as they own smart and portable devices, so they have full knowledge of 
technology, and electronic tests will be very easy for them if we compare them with students about 15 years ago.

The process of moving from the traditional test to the electronic assessment machine was not difficult for academics and students because it was easy for them, and one of the participants confirmed this when he said: I am sure that $100 \%$ of students will not face difficulties in using the electronic exam, because in short it is easy for them and from this point of view this process of moving from the traditional tests that were applied before the Corona pandemic and in the previous period will not be difficult, but it will be easy to adopt the electronic exam.

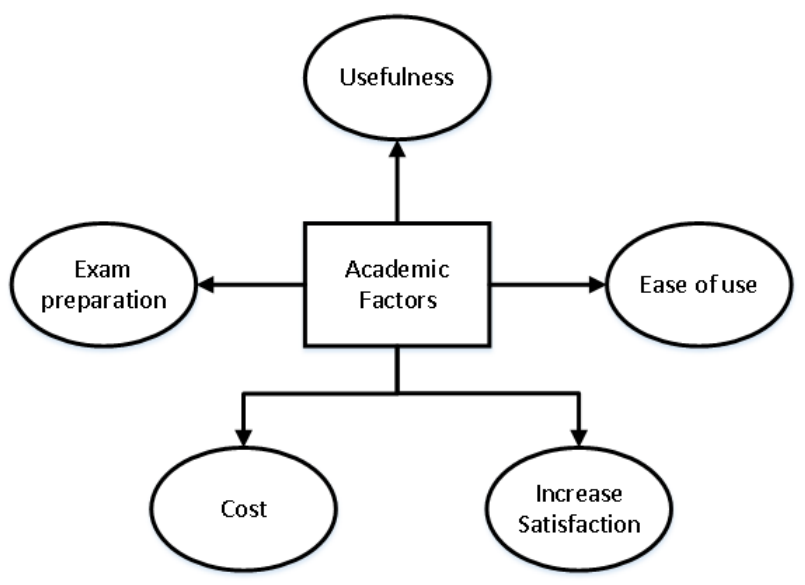

Fig. 3. Academic factors affecting adoption of e-assessment.

\subsection{Exam preparation}

One of the factors that increased the use of electronic assessments is the ease of preparation, and many participants emphasized it, and one of them mentioned that: Honestly, preparing questions on electronic tests is very easy compared to the traditional way of exams. Ease of obtaining evaluation results is one of the important reasons for adopting electronic evaluations, and one of the participants mentioned this thing when he said: Yes, it is true. There is ease in preparing the questions and there is an ease in obtaining the results, which makes the online test one of the easiest methods for us.

The principle of transparency in correction may be a requirement for students and comfortable for academics, and this element is achieved when using electronic assessments. One of the participants mentioned this thing when he said: In electronic exams, I see that corrective deviation is completely non-existent, and this matter achieves the principle of fairness and transparency in correction. 


\subsection{Increased satisfaction}

Satisfaction makes people adopt electronic assessments and continue to use them as they provide solutions for assessments without human intervention, and this was mentioned by one of the participants when he said: I say it in all sincerity. How beautiful it is for the results of the tests to be fast, immediate, and without any human intervention, and this is only done through electronic tests. Feeling satisfied with preparing, following up, and obtaining results makes academics continue to use electronic assessments, and many participants mentioned, for example:

We are generally satisfied with the features that come from the electronic test application, so we are satisfied with the preparation, follow-up and then obtaining the results. This thing makes us want to use it periodically in certain subjects for the benefit of students, teachers and the university. Correction in electronic assessments is very easy, and this matter makes academics feel comfortable, and this thing is confirmed by the participants when he said the following: I add my voice to that of my colleague, that the level of satisfaction is high by using the platform that carries electronic tests, which made us feel comfortable when correcting.

\subsection{Exam quality}

Quality in the electronic assessment is excellent, and this thing was mentioned by one of the participants, for example: I think that the quality of the electronic exam is excellent and that it is a great option in light of the current circumstances, I mean the Corona crisis. Linking the objectives of the course with its outputs is a basic requirement and this is done by means of tests, and electronic assessments are considered one of the means to achieve this thing. From my personal side, I was able to measure the results of the course that I teach through the questions that I ask, and this matter will be reflected in the quality of the electronic tests.

\subsection{Increase enjoyment}

The feeling of enjoyment when using electronic assessment makes this matter more acceptable to academics, and this thing was confirmed by many participants, for example: I feel happy when designing the e-exam, and I feel comfortable uploading it to the e-learning platform. The success of the experience in using electronic assessments makes many participants listen during preparation, and one of the participants confirmed this when he said: I used electronic tests in the first semester and the second semester, and frankly I enjoyed them, which made me think very seriously about using them in the final exam.

\subsection{Cost}

The paper-based test is very expensive in terms of money and effort, but electronic assessments are a great alternative to traditional tests and this is confirmed by the participants when he said: I would like to add an important point that prompted me to 
encourage the use of the electronic exam, which is that the cost of the electronic exam is not worth anything, other than the paper-based test that requires a printer, paper, ink etc. The low cost makes electronic evaluations a good option and a catalyst for adopting this type of test. He asserted many participants when he said: Yes, of course, it is true, because I have experience with the first semester exam, which was remote, that the total cost of this test is zero riyals, and this thing really motivates me and makes me use the electronic test in all the courses I study.

\section{Challenges of Using Electronic Assessment from Academic}

There are a set of challenges that are causing the delay in adopting electronic assessments from the academics' point of view, as shown in Figure 4. These challenges are described in the following.

\subsection{Cheat}

Cheating is one of the reasons that hinder the use of electronic assessments from the academic point of view, because there are students who have a desire to cheat or they have cheated in more than one subject, and one of the participants mentioned that when he said: I can almost assure you that e-tests are not a good option for some students who wish to cheat. The awareness aspect about the importance of electronic tests and their special instructions, including avoiding cheating, is very important, and this thing was confirmed by one of the participants, for example: Frankly, it is imperative to educate students about the importance of the electronic exam and avoid cheating, and this is something the university must do, especially since some students seek the help of experts in the field of specialization in order to obtain high marks. From this standpoint, it is necessary to use modern technology to curb this phenomenon.

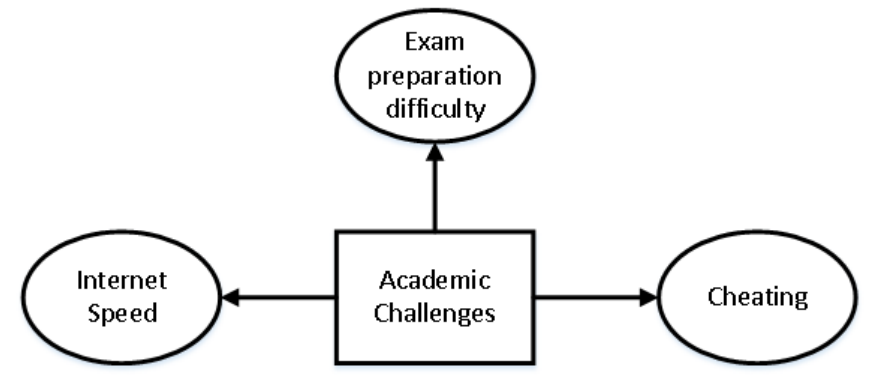

Fig. 4. Challenges facing academic staff.

\subsection{Difficulty preparing for exams}

Some academics who are not specialized in computers face some difficulties when preparing for electronic tests and one of the participants mentioned this thing when he said: We specialize in the field of computers, so designing electronic exams is easy 
for us, but some colleagues in other specialties may find it difficult to prepare and design, so the presence of awareness and training programs is very important for them. Communication with specialists in computers or those who have technical skill is considered an urgent necessity for some academics and this thing was mentioned by one of the participants when he said: I am talking about myself. A colleague called me and asked for help preparing for my first electronic semester exam, so I helped him design. The reason for this was that he was not a specialist and his technical skills were weak. I expect the adoption of electronic exams in some disciplines may be delayed a little.

\subsection{Internet speed}

The speed of the Internet is one of the reasons that speeds up the process of adopting electronic assessments or not, so one of the participants mentioned that he has poor access to the Internet, for example: We suffer from poor internet access in some areas where I live, forcing me to enroll in university to prepare for the test remotely. Slow speed problem is a group problem, and more than one participant confirmed this when he said: I think everyone suffers from the same problem, I mean the Internet, students and teachers, they all have poor internet speed.

\section{Integrated Framework of E-Assessment}

This paper has presented a set of factors that help in adopting e-assessments in the universities from the point of view of students and academics. Also, it has presented the problems and difficulties facing both parties.

Figure 5 shows depicts the integrated framework of the success of E-assessment. It shows that some students encounter a range of difficulties and obstacles as following. Firstly, the most important problem is poor infrastructure in some universities such as the pressure on the systems and their use by a number of users. Secondly, there is some weakness of the Internet in some cities. Thirdly, often, the grading distribution is inconsistent with the number of questions. Fourthly, sometimes, there is no Establishing sufficient test time for students. Finally, there is ambiguity in many instructions about how to use electronic assessments. While academics face a different set of problems, for example cheating, which is one of the reasons that hinder the use of electronic assessments. Also, there is a lack of the awareness about the importance of electronic tests and their special instructions. In addition, some academics who are not specialized in computers face some difficulties when preparing for electronic tests. Finally, the speed of the Internet is not good in some remote areas. 


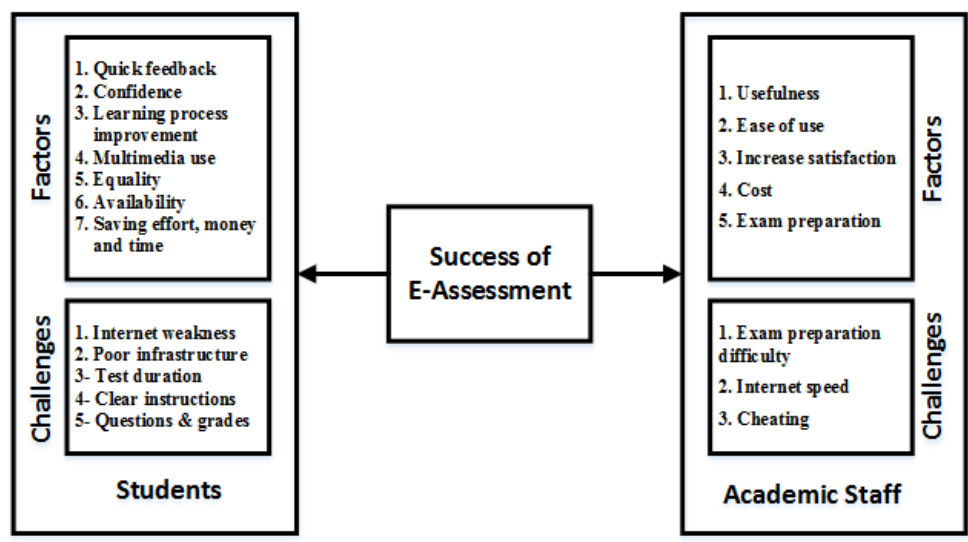

Fig. 5. Integrated framework of the success of E-assessment.

On the other hand, there are a set of factors that help students to use e-assessments, for example, the electronic assessment has the ability to quickly obtain feedback. Also, the students have some confidence when they using electronic assessments, because the concept of bias when using this type of test does not exist. In addition, eassessments have made the learning process continuous. Moreover, traditional tests are not interactive, and when adding some improvements such as audio or video clips, it makes electronic tests distinctive. Also, one of the important features of electronic assessments is the presence of equality and fairness among all students. In addition, the availability of e-assessments at different times is one of the features that distinguish these types of test from others. Finally, one of the advantages that distinguish the e-assessments from other assessments is the saving of time. In the same context, there are some factors that help academics to adopt e-assessments. There is some usefulness of using e-assessments. Also, one of the factors that increased the use of electronic assessments is the ease of use it. In addition, satisfaction about using electronic assessments continue to use them as they provide solutions for assessments without human intervention. Moreover, the feeling of enjoyment when using electronic assessment makes this matter more acceptable to academics. Finally, the paperbased test is very expensive in terms of money and effort, but electronic assessments are a great alternative to traditional tests.

\section{Conclusion and Future Work}

E-learning has become a strategic choice for the continuation of the educational process. Therefore, many universities around the world have compulsively used and applied it on a large scale during the period of the Corona crisis. In addition, the concept of electronic evaluation appeared side by side with the concept of electronic education in order to continue to ensure social distancing. Where this type of evaluations is characterized by overcoming some limitations in the paper evaluation. One of the advantages of an electronic assessment (electronic assessment) is the ability to 
provide feedback to the student immediately. Most universities around the world were providing e-learning to their students as a development option for the education process, on the condition that they attend to take the exam in universities. However, in the Corona crisis, this was not possible, especially in subjects that include a very large number of students. This paper examined a set of factors and challenges that guide the acceptance of electronic assessments in the form of steps. The first step is to gather some information about the benefits and elements that contribute to accepting electronic assessments from the students' point of view. The second step is to gather the most important difficulties and problems students face when using electronic assessments. The third step is to gather some information about the benefits and elements that contribute to the acceptance of electronic assessments from an academic point of view. Fourth step, the most important obstacles to accepting electronic assessments have been collected. All previous steps were taken in order to achieve the last step, which is building an integrated framework that includes controls and procedures that contribute to the success of accepting electronic assessments based on the vision points from the academic and student perspectives. In future studies, we will test integrated framework by using qualitative way through the questionnaires. We will also use a larger sample in four Saudi universities.

\section{References}

[1] N. Alruwais, "An Evaluation of the Model of Acceptance of E-Assessment Among Academics in Saudi Universities," Education Journal, vol. 7, p. 23, 1 2018. https://doi.org/10. 11648/j.edu.20180702.11

[2] H. Essel, S. Nortey and P. Butakor, "Summative E-Examination for High Stake Assessment in Higher Education: A Case of Undergraduate Students at The Kwame Nkrumah University of Science and Technology.," 22019.

[3] E. L. Howe, "Perceptions of e-assessment by students and lecturers," International Journal of Education and Research, vol. 8, p. 143-152, 42020.

[4] S. Gupta and A. Gupta, "E-Assessment Tools for Programming Languages: A Review," 2018.

[5] A. Al-Azawei, W. Baiee and M. Mohammed, "Learners' Experience Towards EAssessment Tools: A Comparative Study on Virtual Reality and Moodle Quiz," International Journal of Emerging Technologies in Learning (iJET), vol. 14, p. 34-50, 2019. https://doi.org/10.3991/ijet.v14i05.9998

[6] C. Adachi, J. H.-M. Tai and P. Dawson, "Academics perceptions of the benefits and challenges of self and peer assessment in higher education," Assessment \& Evaluation in Higher Education, vol. 43, pp. 294-306, 2018. https://doi.org/10.1080/02602938.2017. $\underline{1339775}$

[7] M. Appiah and F. Tonder, "E-Assessment in Higher Education: A Review," vol. 9, pp. 1454-1460, 122018.

[8] H. Alsadoon, "Students' perceptions of e-assessment at Saudi electronic university," Turkish Online Journal of Educational Technology, vol. 16, pp. 147-153, 12017.

[9] A. Mccann, "Factors affecting the adoption of an E-Assessment system," Assessment \& Evaluation in Higher Education - Assess Eval High Educ, vol. 35, pp. 799-818, 122010. https://doi.org/10.1080/02602930902981139 
[10] N. Alruwais, "The factors impacting the acceptance of E-assessment by academics in Saudi universities," University of Southampton, 2018.

[11] N. Alruwais, G. Wills and M. Wald, "Identifying factors that affect the acceptance and use of E-assessment by academics in Saudi Universities," IJAEDU- International E-Journal of Advances in Education, vol. 2, p. 132, 10 2016. https://doi.org/10.18768/ijaedu. $\underline{20012}$

[12] H. Mellar, R. Peytcheva-Forsyth, S. Kocdar, A. Karadeniz and B. Yovkova, "Addressing cheating in e-assessment using student authentication and authorship checking systems: Teachers' perspectives," International Journal for Educational Integrity, vol. 14, p. 2, 2 2018. https://doi.org/10.1007/s40979-018-0025-x

[13] S. Washburn, J. Herman and R. Stewart, "Evaluation of performance and perceptions of electronic vs. paper multiple-choice exams.," Advances in physiology education, vol. 414 , pp. 548-555, 2017. https://doi.org/10.1152/advan.00138.2016

[14] G. Sindre and A. Chirumamilla, "E-exams versus paper exams: A comparative analysis of cheating-related security threats and countermeasures," 2015.

[15] Boudreau, M.C., Gefen, D. and Straub, D.W. (2001). Validation in information systems research: a state-of-the-art assessment. MIS quarterly, pp. 1 16. https://doi.org/10. $\underline{2307 / 3250956}$

[16] Chau, P.Y. (1996). An empirical assessment of a modified technology acceptance model. Journal of management information systems 13 (2), pp. 185204.

[17] Davis, F.D. and Venkatesh, V. (1996). A critical assessment of potential measurement biases in the technology acceptance model: three experiments. International Journal of $\mathrm{Hu}-$ man Computer Studies 45 (1), pp. 19 45.https://doi.org/10.1006/ijhc.1996.0040

[18] Hair, J.F., Black, W.C., Babin, B.J. J., Anderson, R.E. and Tatham, R.L. 2006, variate data analysis 6th Edition. New Jersey: Pearson Education

[19] Uppal, M.A., Gulliver, S.R. and Ali, S.A.M.N.A.N. (2015). Factors Determining ELearning Service Quality. In Advances in Computers and Technology for Education conference, Dubai. 1618 October 2015

[20] Van der Heijden, H. (2003). Factors influencing the usage of websites: the case of a generic portal in The Netherlands. Information \& management, 40 (6), pp. 541549. https://doi.org/10.1016/s0378-7206(02)00079-4

[21] Stokes, R. (2005). Measuring event sponsorship effects in a government to business (G2B) relationship domain. In Australia and New Zealand Marketing Academy Conference (ANZMAC, 2005) 2005), pp. 168173.

[22] Sorensen, J.B. and Sorenson, O. (2003). From conception to birth: Opportunity perception and resource mobilization in entrepreneurship. Advances in Strategic Management 20, pp. 89 118. https://doi.org/10.1016/s0742-3322(03)20003-6

[23] McIvor, R., McHugh, M. and Cadden, C. (2002). Internet technologies: supporting transparency in the public sector. International Journal of Public Sector Management 15 (3), pp. 170 187. https://doi.org/10.1108/09513550210423352

[24] Malhotra, Y. and Galletta, D.F. (1999). Extending the technology acceptance model to account for social influence: Theoretical bases and empirical validation. In Systems sciences, 1999. HICSS 32. Proceedings of the 32nd annual Hawaii international conference on. pp. 14. IEEE. https://doi.org/10.1109/hicss.1999.772658

[25] Lai, V.S. and Li, H. (2005). Technology acceptance model for internet banking: an invariance analysis. Information \& management 42 (2), pp. 373 386. https://doi.org/10. 1016/j.im.2004.01.007 
[26] Jackson, C.M., Chow, S. and Leitch, R.A. (1997). Toward an understanding of the behavioral intention to use an information system. Decision sciences, 28 (2), pp.357 389. https://doi.org/10.1111/j.1540-5915.1997.tb01315.x

[27] Hunt, S.D., Sparkman Jr, R.D. and Wilcox, J.B. (1982). The pretest in survey research: Issues and preliminary findings. Journal of Marketing Research, pp. 269273. https://doi.org/10.1177/002224378201900211

[28] Hu, L.T. and Bentler, P.M. (1998). Fit indices in covariance structure modeling: Sensitivity to under-parameterized model misspecification. Psychological methods 3 (4) https://doi.org/10.1037/1082-989x.3.4.424

[29] Hair, J.F., Black, W.C., Babin, B.J. J., Anderson, R.E. and Tatham, R.L. (2006) variate data analysis 6th Edition. New Jersey: Pearson Education

[30] Cavana, R.Y., Delahaye, B.L. and Sekaran, U. (2001). Applied business research: Qualitative and quantitative methods. John Wiley \& Sons

\section{Author}

Dr. Sultan Refa Alotabi is an Assistant Professor and Dean in the College of Computing and Information Technology (CCIT) at Shaqra University, Kingdom of Saudi Arabia. His research interests include E-Government, E-Services, E-Health and Knowledge Management. He continued to contribute also to the development of various projects and systems; much of his work has been in embracing digital transformation and improving the current technology to solve challenges facing the College of Computing and Information Technology. Email: sultanrefa@su.edu.sa

Article submitted 2021-02-15. Resubmitted 2021-03-17. Final acceptance 2021-03-18. Final version published as submitted by the authors. 